ORIGINAL ARTICLE

\title{
Is bowling workload a risk factor for injury to Australian junior cricket fast bowlers?
}

\author{
R J Dennis, C F Finch, P J Farhart
}

Br J Sports Med 2005;39:843-846. doi: 10.1136/bjsm.2005.018515

See end of article for authors' affiliations

......................

Correspondence to: Rebecca J Dennis, University of New South Wales, NSW Injury Risk Management Research Centre, Sydney, Australia; rebecca.dennis@unsw. edu.au

Accepted 19 April 2005
Objectives: To examine whether bowling workload is a risk factor for overuse injury to Australian junior cricket fast bowlers and to evaluate the appropriateness of current bowling workload guidelines.

Methods: Forty four male fast bowlers (mean (standard deviation) age 14.7 (1.4) years) were monitored prospectively over the 2002-2003 season. Bowlers completed a daily diary to record bowling workloads and self reported injuries, which were validated by a physiotherapist. Bowling workload prior to the first injury (for those bowlers who were injured) was compared to workload across the whole season for uninjured bowlers.

Results: Eleven (25\%) bowlers reported an overuse-type injury, with seven of these sustaining a back injury. Injured bowlers had been bowling significantly more frequently than uninjured bowlers (median number of days since the previous bowling day: $3.2 \vee 3.9$ days, Mann-Whitney $U=105.0, p=0.038$ ). Compared with bowlers with an average of $\geqslant 3.5$ rest days between bowling, bowlers with an average of $<3.5$ rest days were at a significantly increased risk of injury (risk ratio $(R R)=3.1,95 \%$ confidence interval (CI) 1.1 to 8.9 ). There were also trends towards an increased risk of injury for those who bowled an average of $\geqslant 2.5$ days per week ( $R R=2.5,95 \% \mathrm{Cl} 0.9$ to 7.4$)$ or $\geqslant 50$ deliveries per day $(R R=2.0,95 \% \mathrm{Cl}$ 0.7 to 5.4$)$.

Conclusions: This study has identified high bowling workload as a risk factor for overuse injury to junior fast bowlers. Continued research is required to provide scientific evidence for bowling workload guidelines that are age-specific for junior fast bowlers.
C icket is one of Australia's most popular sports, with a total of 410919 participants in organised programs in were aged under 18 years. ${ }^{1}$ Unfortunately, participation is associated with a risk of injury and a number of studies have documented the incidence of injury amongst both junior and senior players. ${ }^{2-8}$ Fast bowlers have consistently been identified as being at the greatest risk of injury, with a combination of predisposing factors including poor technique, poor physical preparation, and overuse. ${ }^{7-11}$ Indeed, overuse has been identified as a major contributing factor to the occurrence of injury, particularly amongst young fast bowlers. $^{4}$

Overuse injuries are generally the result of repetitive microtrauma where a number of forces, each lower than the critical limit of the specific tissue, combine to produce a fatigue effect over time. ${ }^{12}$ The developing musculoskeletal system is particularly vulnerable to overuse, with sites of vigorous development in long bones and musculotendinous attachments being areas of potential injury. ${ }^{13}{ }^{14}$ Participants in a number of activities, particularly those which require repetitive hyperextension of the lumbar spine (such as fast bowling), may experience low back pain as rapid growth of the vertebral bodies is not matched by that of the dorsal soft tissues. ${ }^{13}$ The increased elasticity of the intervertebral disc, which may allow a greater proportion of torsional forces to reach the vertebrae, ${ }^{15}$ incomplete ossification of the posterior vertebral elements until about 25 years of age, ${ }^{16}$ and incomplete formation of the iliolumbar ligament (which may be a very important stabiliser of the lumbosacral junction) until the third decade of life ${ }^{17}{ }^{18}$ can each increase the propensity of junior athletes to injury. The most serious overuse injuries for young fast bowlers are those to the pars interarticularis, as they can potentially limit participation in the game for extended periods. ${ }^{11} 19$
While most previous aetiological research with fast bowlers has focused on biomechanical analyses of technique, few studies have examined bowling workload as an injury risk factor. Our study of Australian first class fast bowlers (mean age 27 years) found that bowling workload was highly associated with overuse injury, ${ }^{20}$ as did a study with Australian junior fast bowlers. ${ }^{9}$ In contrast, injury incidence was not higher in those that bowled the most in a cohort of young English fast bowlers. ${ }^{21}$

The Australian Junior Cricket Policy outlines bowling workload guidelines for junior fast bowlers, describing the maximum number of deliveries to be bowled in matches and training sessions for players aged $<19$ years. ${ }^{22}$ The findings of our research conducted with senior fast bowlers ${ }^{20}$ raised concerns about the appropriateness of the junior fast bowling workload guidelines, which are based on current best practice. In some cases, junior bowlers are permitted to bowl more than research has suggested is appropriate for senior fast bowlers (table 1). ${ }^{20}$ In response to this disparity, Cricket Australia commissioned this study with junior fast bowlers. Thus, the aim of this study was to investigate bowling workload as a risk factor for injury to junior fast bowlers and evaluate the appropriateness of current bowling workload guidelines.

\section{METHODS}

Forty four male fast bowlers participating in club and district cricket with a mean (standard deviation) age of 14.7 (1.4) years (range 12-17 years) were prospectively monitored over the 2002-2003 Australian summer cricket season. A fast bowler was defined as a bowler for whom the wicketkeeper

Abbreviations: $\mathrm{Cl}$, confidence interval; $\mathrm{MRI}$, magnetic resonance imaging; $R R$, risk ratio 
Table 1 Current workload guidelines for junior fast bowlers and recommendations from research with first class fast bowlers

\begin{tabular}{llllll}
\hline $\begin{array}{l}\text { Age group } \\
\text { lyears) }\end{array}$ & $\begin{array}{l}\text { Number of deliveries } \\
\text { per match innings }\end{array}$ & $\begin{array}{l}\text { Number of training } \\
\text { sessions per week }\end{array}$ & $\begin{array}{l}\text { Number of deliveries } \\
\text { per training session }\end{array}$ & $\begin{array}{l}\text { Maximum sessions } \\
\text { per week }\end{array}$ & $\begin{array}{l}\text { Maximum deliveries } \\
\text { per week }\end{array}$ \\
\hline Under 13 & 48 & 2 & 30 & 3 & 108 \\
Under 15 & 60 & 2 & 36 & 3 & 132 \\
Under 17 & 96 & 3 & 36 & 4 & 204 \\
Under 19 & 120 & 3 & 42 & 4 & 246 \\
First class* & N/A & 1 & 40 & 3 & 188 \\
\hline
\end{tabular}

*Findings from research conducted with fast bowlers with a mean age of 27 years. ${ }^{20}$ All other data are from Cricket Australia's Junior Cricket Policy.

would normally stand back from the stumps, due to the increased speed of the ball when bowled. ${ }^{20}{ }^{23}$

Bowlers participating in this study were part of a larger prospective cohort study with both junior and senior fast bowlers undergoing a range of tests. The sample size for the larger cohort study (from which the junior participants were recruited for this bowling workload study) was largely determined by the resources required to complete the comprehensive testing protocols. All participants and their parents/guardians gave written, informed consent. Ethics approval was obtained from the Australian Institute of Sport.

Participants completed detailed logbooks, recording the number of match and training deliveries bowled each day for the duration of the 6 month season. This diary was forwarded on a weekly basis and entered into a central database. Bowling completed in organised 1 or 2 day matches was categorised as match workload. Training workload included formal training and informal personal training.

The definition of injury was adapted from that previously used. ${ }^{20}$ An injury was defined as a condition that affected availability for team selection, limited performance during a match, or required surgery. Minor injuries which only affected participation in training sessions were not examined in this study. Injuries included in the analysis were overusetype injuries as a result of bowling. ${ }^{20}$ Therefore, all injuries had an insidious onset caused by repetitive episodes of microtrauma, rather than collision-type injuries. Bowlers were asked to report any condition or injury in their logbooks, even if unrelated to cricket. The bowlers were then contacted by a sports physiotherapist and each case was reviewed to determine if the injury met the inclusion criteria. As part of the larger cohort study, all bowlers underwent a magnetic resonance imaging (MRI) scan at the start of the season and immediately after any back/trunk injury. The results of the post-injury scan were used by the sports physiotherapist to confirm the injury diagnosis for this study. While MRI may not be the most sensitive radiological modality for diagnosis of lumbar bone stress injury, ${ }^{24}$ it was chosen because of the issues of radiation exposure for adolescents associated with CT scan or bone scan. ${ }^{25}$

To evaluate the relationship between workload and injury, comparisons were made between injured and uninjured bowlers. ${ }^{20}$ For those that were injured, only workload prior to the occurrence of injury was examined. For those that remained uninjured, workload for the entire season was reported. While all injuries were recorded, if a bowler sustained multiple injuries or recurrences of an injury during the season, only workload prior to the first injury is reported in this paper.

Data analysis was undertaken with SPSS (Chicago, IL, USA). Independent $t$ tests and Mann-Whitney $U$ tests (a distribution-free test which rank-orders data) were used for parametric and non-parametric data, respectively. The risk of injury for particular workloads was assessed by risk ratios (RR) and associated 95\% confidence intervals (95\% CI) as estimated from $2 \times 2$ tables. Risk ratios were considered to be significantly different if the $95 \%$ CI excluded the value 1.0 .

\section{RESULTS}

The 44 players bowled on a total of 1783 bowling days, of which $39 \%$ were match days and $61 \%$ were training days. They bowled on an average of 1 match day and 1.5 training days per week, with an average of 55 and 36 deliveries per match and training day, respectively.

Eleven of the 44 bowlers (25\%) reported a bowling related overuse injury during the season. Six of these injuries occurred in the first half of the season and the remaining five occurred in the second half of the season. Seven of the injured bowlers sustained a back injury (one bilateral stress fracture to the pars interarticularis, three stress reactions to the pars interarticularis contralateral to the bowling arm, one stress reaction to the pars interarticularis on the bowling side, and two lumbar musculoligamentous strains). Other injuries recorded were muscular strains to the shoulder and quadriceps, and calcaneal apophysitis. While not meeting the injury inclusion criteria, it is worth noting that 23 of the 44 bowlers $(52 \%)$ reported back pain at some stage during the season. There was no difference in the mean age of the injured and uninjured bowlers (14.8 and 14.7 years, respectively).

Bowling workloads were examined to determine if the players had been exceeding the Cricket Australia Junior Cricket Policy guidelines (table 1). ${ }^{22}$ Bowlers had exceeded the guidelines for the number of match deliveries to be bowled per day on only $8 \%$ of the match days. However, they exceeded the guidelines for the number of training deliveries to be bowled per day on $42 \%$ of the training days (median: 12 deliveries in excess of guidelines, range: 1-264 deliveries).

In comparing workloads, injured players bowled significantly more frequently, with the median number of days since the previous bowling day lower in injured bowlers compared with uninjured bowlers (median: $3.2 v 3.9$ days, M rank: 171.0 and 819.0, respectively, Mann-Whitney $\mathrm{U}=105.0, \mathrm{p}=0.038$ ). There was a trend towards an increased injury risk for those bowlers with a high mean bowling workload, as measured by frequency of bowling days, days per week, and deliveries per day (table 2). There was no association found between the average number of deliveries bowled per week and injury.

\section{DISCUSSION}

This study is the first to examine the actual number of deliveries bowled by junior fast bowlers over the course of an entire cricket season. The importance of this sort of information to inform the development of evidence based guidelines for junior cricket programs has been recognised by the NSW Sporting Injuries Committee and Cricket Australia, who jointly funded this study.

Overall, the results suggest there is a relationship between high bowling workload and injury. As with first class fast bowlers, $^{20}$ increased bowling frequency is significantly associated with increased injury risk. Parents and coaches should be aware that programs designed for senior fast bowlers are not appropriate for junior players, who may be more prone to overuse injury because their bones and 
Table 2 The risk of injury in junior fast bowlers according to mean bowling workload and the percentage of injured and uninjured bowlers with a high bowling workload

\begin{tabular}{|c|c|c|c|c|}
\hline Mean bowling workload & $\begin{array}{l}\% \text { of injured bowlers } \\
\text { with this workload } \\
(n=11)\end{array}$ & $\begin{array}{l}\% \text { of uninjured } \\
\text { bowlers with this } \\
\text { workload }(n=33)\end{array}$ & $\begin{array}{l}\text { Risk of injury as } \\
\text { compared with bowlers } \\
\text { with a lesser workload }\end{array}$ & $95 \% \mathrm{Cl}$ \\
\hline $\begin{array}{l}<3.5 \text { days rest between bowling } \\
\geqslant 2.5 \text { days per week } \\
\geqslant 50 \text { deliveries per day } \\
\geqslant 100 \text { deliveries per week }\end{array}$ & $\begin{array}{l}64 \% \\
64 \% \\
45 \% \\
45 \%\end{array}$ & $\begin{array}{l}27 \% \\
33 \% \\
24 \% \\
39 \%\end{array}$ & $\begin{array}{l}3.1 \\
2.5 \\
2.0 \\
1.2\end{array}$ & $\begin{array}{l}1.1 \text { to } 8.9 \\
0.9 \text { to } 7.4 \\
0.7 \text { to } 5.4 \\
0.4 \text { to } 3.4\end{array}$ \\
\hline
\end{tabular}

ligaments are not fully developed..$^{911}{ }^{15-18} 26$ It is, therefore, important that workload guidelines are specific to junior players, as direct extrapolation from senior fast bowlers may not be appropriate due to these physical, growth related factors.

As shown in table 1 , the recommended workloads for junior players in some cases exceed what has been suggested as being appropriate for much older players. It was not possible to stratify the analysis according to age group because of the small sample size and this study is therefore limited in its ability to propose changes in the guidelines for specific age groups. However, given the importance of bowling frequency, it does seem that rest days should be added to the guidelines. The results indicated that bowling more frequently than every 3.5 days (on average during the season) significantly increased injury risk. Bowlers also need to consider the amount of bowling completed during training or informal practise sessions. While the bowlers adhered to the match workload guidelines listed in the Junior Cricket Policy $^{22}$ (which are enforced by umpires), on $42 \%$ of training days they exceeded the recommended number of deliveries. As with baseball, match guidelines can be enforced, but there is the potential for dramatically increased numbers of deliveries in an informal setting. ${ }^{27}$

Fewer junior fast bowlers sustained a bowling related overuse injury than has been reported using the same methodology for senior fast bowlers (25\% v 59\%, respectively). ${ }^{20}$ The rate of injury is also less than the $47 \%$ reported for South African schoolboy cricketers. ${ }^{6}$ However, the comparability of these findings is limited, as the South African study reported injuries to bowlers in general and it is not clear what proportion of this group were fast bowlers. Furthermore, a more inclusive definition of injury was used. In a study of 70 young English fast bowlers, an injury rate of 32.8 per 100 bowlers was reported..$^{21}$ Although the definition of injury used was similar to ours, the analysis was not restricted to overuse-type injuries. ${ }^{21}$

Back injuries have been the focus of most previous research, as they can potentially limit participation in the game for extended periods. ${ }^{911}{ }^{19}$ Foster et al reported that 38\% of the 82 Australian fast bowlers in their study sustained a back injury. ${ }^{9}$ In the English junior fast bowlers study, $10 \%$ of bowlers reported back pain during the study period and one bowler sustained a stress fracture. ${ }^{21}$ The frequency of bowlers reporting back pain (52\%) and back injury (16\%) in our study differed from the results of this previous research. As our definition of injury was comparable to the definitions in these two studies, ${ }^{921}$ the dissimilarity in findings could be a result of differing bowling techniques, physical characteristics, or workloads of the participants. Foster et al found that both bowling technique and high workload were associated with injury, with $59 \%$ of the participants who bowled more than the mean number of matches for the group suffering a back injury, as compared with the overall back injury frequency of 38\%. ${ }^{9}$ In comparison, the English study found there was no increased injury risk in those that bowled the most. ${ }^{21}$ However, in both prior studies, it appears that bowlers were compared according to the total number of sessions/ deliveries bowled during the entire 6 month study period, which may include bowling completed after injury. We restricted our analysis to include bowling completed prior to injury (if any), due to the importance of distinguishing between injury risk factors and injury sequelae. ${ }^{28}$ Also, as exposure was clearly established before injury, any potential bias associated with recall of risk exposure and injury history was eliminated. ${ }^{29}$ The fact there was no difference between the workloads of injured and uninjured English fast bowlers may simply be because the injured bowlers could not bowl for a significant period of time after injury.

Another factor limiting direct comparison of the results with the English junior study, is that the latter examined workload and injury in 3 months of preseason training and the first 3 months of the season, while we monitored the 6 month cricket season. ${ }^{21}$ As was noted by the authors of the English study, ${ }^{21}$ injuries can become manifest after the study period, which in their case was the second half of the season. In our study, five of the 11 injuries occurred during that period. Therefore, it is possible that the English study found no relationship between injury risk and bowling workload because injuries may have occurred in the second half of the season, by which time the opportunity to bowl in matches (and bowling workload) would have increased greatly. However, it is also acknowledged that unless bowlers are monitored all year, or for subsequent seasons, injuries may become manifest after any selected study period.

While this study has the potential to contribute important information, we also recognise its limitations. The intensity of bowling was not considered in this study and it is acknowledged that not all deliveries recorded during the season would have been bowled at full pace. However, it is not practical to record the speed of every delivery bowled throughout the season with a radar gun and a self reported measure of bowling intensity is subjective and may be misreported. ${ }^{20}$ Furthermore, to allow comparison with the existing bowling workload guidelines, bowling workload was only measured in terms of days bowled, rather than the actual duration of bowling spells and time between spells. Future research could consider rest periods and optimal fast bowling work to rest schedules in greater detail.

The small sample size resulted in a lack of power to detect small to moderate differences in the bowling workload of injured and uninjured bowlers and prevented the conduct of multivariate analysis. Continued research with a larger sample will allow multiple measures to be examined as possible injury risk factors and will also allow trend analysis for injury risk according to stratified bowling workloads. This may provide more detailed information about the possible injury risk with under-bowling and over-bowling, as has been provided with senior fast bowlers. ${ }^{20}$ It may also be possible that similar risk factors will need to be weighted differently across different age groups because of the anatomical and physiological differences between adolescents and adults. 


\section{What is already known on this topic}

Fast bowlers have consistently been identified as the cricket players at the greatest risk of injury, with a combination of predisposing factors including poor technique, poor physical preparation, and overuse. Previous research has reported that bowling workload is a significant risk factor for overuse injury to first class fast bowlers.

\section{What this study adds}

High bowling workload has been identified as a risk factor for overuse injury to junior fast bowlers. As with first class fast bowlers, increased bowling frequency is significantly associated with increased injury risk. Rest days should be considered for inclusion in bowling workload guidelines.

Future research may be able to determine if high bowling workload is a more potent risk factor for injury to junior fast bowlers as compared with senior fast bowlers.

\section{ACKNOWLEDGEMENTS}

We would like to thank Cricket NSW, ACT Cricket, the Sutherland Shire Junior Cricket Association, Marc Portus, Chris Goumas, Andrew Hayen, and the participating fast bowlers, for their assistance.

\section{Authors' affiliations \\ R J Dennis, C F Finch, University of New South Wales, Sydney, Australia P J Farhart, Cricket NSW, Paddington, NSW, Australia}

We would like to thank the NSW Sporting Injuries Committee and Cricket Australia for funding this project. RD was supported by an NHMRC PhD scholarship and CF was supported by an NHMRC Principal Research Fellowship

Competing interests: the authors would like to acknowledge that Cricket Australia and the NSW Sporting Injuries Committee provided research funding for this project, as outlined in this paper. The funding was provided in the interests of developing appropriate injury prevention strategies for the sport of cricket and neither organisation in any way restricted or censored the findings reported in this paper

Ethics approval: written consent was provided by both the participants and their parents/guardians. The Australian Institute of Sport Ethics Committee provided approval for this project (c/o Australian Sports Commission, PO Box 176, Belconnen ACT 2616, Australia)

\section{REFERENCES}

1 Cricket Australia. National cricket census 2003-04. Melbourne, Australia: Cricket Australia, 2004.

2 Orchard J, James T, Alcott E, et al. Injuries in Australian cricket at first class level 1995/1996 to 2000/2001. Br J Sports Med 2002;36(4):270-4.

3 Finch C, Valuri G, Ozanne-Smith J. Sport and active recreation injuries in Australia: evidence from emergency department presentations. $\mathrm{Br} J$ Sports Med 1998;32(3):220-5.

4 Stretch RA. Cricket injuries: a longitudinal study of the nature of injuries to South African cricketers. Br J Sports Med 2003;37(3):250-3.

5 Leary T, White JA. Acute injury incidence in professional county club cricket players (1985-1995). Br J Sports Med 2000;34(2): 145-7.

6 Stretch RA. The seasonal incidence and nature of injuries in schoolboy cricketers. S Afr Med J 1995;85(11):1182-4.

7 Stretch RA. The incidence and nature of injuries in first-league and provincial cricketers. S Afr Med J 1993;83(5):339-42.

8 Gregory PL, Batt ME, Wallace WA. Comparing injuries of spin bowling with fast bowling in young cricketers. Clin J Sport Med 2002;12(2):107-12.

9 Foster D, John D, Elliott B, et al. Back injuries to fast bowlers in cricket: a prospective study. Br J Sports Med 1989;23(3):150-4.

10 Burnett A, Elliott B, Foster D, et al. The back breaks before the wicket: the young fast bowler's spine. Sport Health 1991;9(4):11-15.

11 Elliott BC, Hardcastle PH, Burnett AF, et al. The influence of fast bowling and physical factors on radiologic features in high performance young fast bowlers. Sports Med Training Rehabil 1992;3(2):113-30.
12 Elliott B. Overuse injuries in sport: a biomechanical approach. Saf Sci Monit 1999;3:1-6.

13 Gerrard DF. Overuse injury and growing bones: the young athlete at risk. Br J Sports Med 1993;27(1):14-18.

14 Difiori J. Overuse injuries in children and adolescents. Physician Sports Med 1999;27(1):75-89.

15 Hadley MN, Zabramski JM, Browner CM, et al. Pediatric spinal trauma. Review of 122 cases of spinal cord and vertebral column injuries. J Neurosurg 1988;68(1):18-24.

16 Warwick R, Williams PL, eds. Gray's anatomy, 35th British ed. Philadelphia: WB Saunders, 1973.

17 Chow DH, Luk KD, Leong JC, et al. Torsional stability of the lumbosacral junction. Significance of the iliolumbar ligament. Spine 1989;14(6):611-5.

18 Luk KD, Ho HC, Leong JC. The iliolumbar ligament. A study of its anatomy, development and clinical significance. J Bone Joint Surg Br 1986;68(2): 197-200.

19 Annear PT, Chakera TM, Foster DH, et al. Pars interarticularis stress and disc degeneration in cricket's potent strike force: the fast bowler. Aust N Z J Surg 1992;62(10):768-73.

20 Dennis R, Farhart $P$, Goumas $C$, et al. Bowling workload and the risk of injury in elite cricket fast bowlers. J Sci Med Sport 2003;6(3):359-67.

21 Gregory PL, Batt ME, Wallace WA. Is risk of fast bowling injury in cricketers greatest in those who bowl most? A cohort of young English fast bowlers. Br J Sports Med 2004;38(2):125-8.

22 Cricket Australia. Junior cricket policy. Melbourne, Australia: Cricket Australia, April, 2004

23 Dennis $R$, Farhart $P$, Clements $M$, et al. The relationship between fast bowling workload and injury in first-class cricketers: a pilot study. J Sci Med Sport 2004; $7(2): 232-6$

24 Saifuddin A, Burnett SJ. The value of lumbar spine MRI in the assessment of the pars interarticularis. Clin Radiol 1997;52(9):666-71.

25 Cross TM, Smart RC, Thomson JE. Exposure to diagnostic ionizing radiation in sports medicine: assessing and monitoring the risk. Clin J Sports Med 2003;13(3): 164-70.

26 Elliott B, Burnett A, Stockhill N, et al. The fast bowler in cricket: a sports medicine perspective. Sports Exerc Inj 1995;1(4):201-6.

27 Micheli L. Sports injuries in children and adolescents. Questions and controversies. Clin Sports Med 1995;14(3):727-45.

28 Bahr R, Holme I. Risk factors for sports injuries - a methodological approach. Br J Sports Med 2003;37(5):384-92.

29 Walter SD, Sutton JR, Mclntosh JM, et al. The aetiology of sport injuries: a review of methodologies. Sports Med 1985;2:47-58.

\section{COMMENTARIES}

Cricket is a popular team sport on the world stage, yet there have been relatively few publications in the medical literature regarding cricket injuries. Identifying risk factors for injury is an important component of any scientific research that aims to reduce injury incidence in sport. It cannot be assumed that research findings in the adult population can be applied to the teenage/young adult population. For these reasons this is a particularly worthwhile study that has identified bowling workload as a risk factor for overuse injury in junior fast bowlers. As the authors state, further research into various parameters of workload is required to provide more specific guidelines regarding volume, frequency, and age specificity.

Trefor James

Lifecare Prahran Sports Medicine, 316 Malvern Rd, Prahran, Victoria 3146, Australia; tjames3@bigpond.net.au

Bowling workloads have been identified as a major risk factor associated with injury in young fast bowlers around the world. As a result most major cricket playing countries have introduced some form of restriction on the number of overs a fast bowler may bowl in practice sessions and in matches. These workloads have not been based on any evidence based research. This is thus the first study that aims to quantify the volume of bowling that the developing musculoskeletal system is able to cope with before an injury results and thus provides coaches, trainers, fast bowlers, and parents with valuable information.

R A Stretch

Nelson Mandela Metropolitan University, Sport Bureau, Port Elizabeth, South Africa; richard.stretch@nmmu.ac.za 